\title{
THE ESTIMATION OF GLOMERULAR FILTRATION RATE (GFR) FOR RENAL SPLIT FUNCTION WITH ${ }^{99 M}$ TC-DTPA
}

\author{
Alamgir Hossain ${ }^{1 *}$, Bedarul Islam ${ }^{2}$, Chanchal K. Ckaki ${ }^{3}$, Samirun Kumar Shaha $^{4}$, Shariful I. Chowdhury ${ }^{5}$ \\ ${ }^{* 1,2,3}$ Department of Physics, University of Rajshahi, Rajshahi-6205, Bangladesh \\ ${ }^{4}$ Pabna University of Science \& Technology \\ ${ }^{5}$ Institute of Nuclear Medicine and Allied Sciences, Rajshahi, Bangladesh
}

Correspondence Author: -

E-mail: alamgir_ru07@yahoo.com

\begin{abstract}
: -
Introduction: To study the variation of kidney counts, uptake and Glomerular filtration rate with renal split function, 27 patient's renogram data were taken. Therefore, to investigate of glomerular filtration rate (GFR) for renal split function with ${ }^{99 m} T c$-DTPA.

Procedures: The injected dose was calibrated by the dose calibrator. About $3 m C i{ }^{99 m} T c$ with DTPA are taken into the syringe. With the help of gamma camera, the pre syringe counts (in Kcpm units) and post syringe counts (Kcpm units) are measured. From the value of pre syringe counts and post syringe counts, the net injected counts are measured. Then the patient is placed on the imaging beds and the detector of the gamma camera is placed on the suitable position. The gamma rays are counted by the detector of the gamma camera, in which emits from the kidney of the patients and the display unit shows the curve time versus counts per minute, Renal split function, uptake, Glomerular filtraration rate, kidney depth, and time of maximum counts for left and right kidney respectively by automated software (Easy softSemence signature series) programm.

Results: The renal split function were investigated in the range of (89.99 22.4) \% for left kidney and also (99.6 6.377) \% for right kidney. It was found that the range of uptake (\%), (8.019 2.2236) \% for left kidney and (7.765 1.19) \% for right kidney. The GFR were found in the range of (72.4 20.4) $\mathrm{ml} / \mathrm{min}$ for left kidney and also (70.9 3.937) for right kidney.

Conclusion: The GFR was linear relationship with renal split functions but linearly decreased with patient's age. For majority patients, the calculated value of GFR were (20-30) $(\mathrm{ml} / \mathrm{min})$ and (40-50) $(\mathrm{ml} / \mathrm{min})$ in left and right kidney respectively. Therefore, majority patient was affected in cardiovascular disease (CVD).
\end{abstract}

Keyword's: - Renal split function $\bullet$ glomerular filtration rate ${ }^{\cdot 99 m} T c$ - DTPA 


\section{INTRODUCTION}

In Tc-99m-DTPA renography, the glomerular filtration rate (GFR) is calculated without blood or urine sampling [1]. Several techniques have been applied in clinical practice, because of technical simplicity and requirement for less time for the patients. The method (Gate) introduced by Gates [2] has been most common in the routine setting. Although the diagnostic accuracy of the gamma camera methods is debated,[3-11] the program is provided as a software package by manufacturers in commercially available computer systems dedicated for nuclear medicine.

The GFR can also be calculated from serum creatinine using the Cockcroft-Gault equation[12] (CG). In Gates and CG, 24-hour creatinine clearance was chosen as a reference. The equations for predicting the GFR are based on the linear relationship of the renal uptake of Tc-99m-DTPA in the Gates and serum creatinine in the CG. A plasma sample clearance method following a single injection of radioactive marker has been proved accurate for quantification of renal function [13-16].

Technetium-99m-Diethylene TriaminePenta Acetic acid (99mTc-DTPA) is a chelating agent which was introduced into renal nuclear medicine in 1970. 99mTc-DTPA is the least expensive renal radiopharmaceutical. It is cleared by the glomerulus and can be used to measure glomerular filtration rate (GFR), [17].The extraction fraction (the percentage of the agent extracted with each pass through the kidney) of $99 \mathrm{mTc}-\mathrm{DTPA}$ is approximately $20 \%$; for this reason, in patients with impaired renal function this radiopharmaceutical may not be as useful as those with higher extraction efficiencies such as 99mTc-mercaptoacetyletriglycine(MAG3) and iodine-131 or iodine-123 orthoiodohippurate(OIH) [18].

Split renal function (SRF), differential renal function, or relative kidney function can be expressed as a percent of total renal function. In determination of Split renal function (SRF), various methods, such as radionuclide methods, triphasic computed tomography (CT), magnetic resonance imaging (MR) and ultrasound Doppler techniques, etc. can be used [1921]. SRF is traditionally measured by radionuclide renal scintigraphies, using different tracers [19]. 99mTcdimercaptosuccinicacid (99mTc-DMSA) is an agent that is actively taken up by the proximal and distal renal tubular cells, directly from the peritubular vessels, and accumulates in the renal cortex [22].

This modality is primarily used for imaging functioning cortical mass and individual renal function [23]. It is the most reliable method for assessing chronic cortical scarring [24]. 99mTc-diethylenetriaminepentacetate (99mTcDTPA) is an agent that is freely filterable at the glomerulus, but it is neither secreted nor resorbed by the kidney tubules. This method is used to measure total and individual kidney functions. By using the gamma camera technique, glomerular filtration rate (GFR) is calculated for each kidney [25].

99mTc-mercaptoacetyltriglycine (99mTc-MAG3) is a renal plasma flow agent almost exclusively excreted by secretion in the proximal tubules and not reabsorbed by the renal tubules. This agent is good for evaluation of renal tubular function [25]. Using a procedure similar to 99mTc-DTPA scintigraphy, dynamic imaging by gamma camera is obtained. Effective renal plasma flow (ERPF), reflecting kidney function, is calculated for each kidney [26]. The purpose of the study was to investigate of glomerular filtration rate (GFR) for renal split function with ${ }^{\mathrm{m}}$ Tc-DTPA.

\section{Methods}

\section{Radiopharmaceutical}

In nuclear medicine technique, very small amount of suitable radiopharmaceutical is administrated orally or intravenously, which accumulated preferentially in certain organs of the patient. Gamma rays from the desired organ can be detected and image can be obtained by using rectilinear scanner or scintillation camera. Imaging or function tests of different organs are possible by using proper compound tagged with appropriate radioisotope. In fact this is the basis of nuclear medicine technique. However, all radioisotopes are not suitable for imaging. In fact a very few of more than 1100 radioisotopes are used for clinical purposes. The suitability of a radioisotope to be tagged with a compound is simply called the radiopharmaceutical [27].

\section{${ }^{99 m}$ Tc Radiopharmaceutical}

Technetium-99m $(99 \mathrm{mTc})$ is widely used in radiopharmaceutical preparations due to its excellent physical and chemical properties. In fact, more than $80 \%$ of all radiopharmaceuticals used in diagnostic nuclear medicine are based on this short-lived radionuclide, which is obtained by elution of a $99 \mathrm{Mo} / 99 \mathrm{mTc}$ generator system that is available in any radio pharmacy and nuclear medicine facility. $99 \mathrm{mTc}$ decays with a half-life of $6 \mathrm{~h}$ by isomeric transition and emission of $140.5-\mathrm{keV}$ gamma radiation. Large amounts of radioactivity may be used with the single- photon emission computed tomography (SPECT) technology, producing high-contrast images with the gamma camera. In fact, the energy window of the gamma camera is optimized to $140.5 \mathrm{keV}(110-220 \mathrm{keV}) .99 \mathrm{mTc}$ is eluted from the generator as a pertechnetate anion. It has been demonstrated that heptavalent technetium must be reduced to a lower valence state in order to be chemically reactive for labeling. Most $99 \mathrm{mTc}$ pharmaceuticals comprise complexes of $99 \mathrm{mTc}$ at various oxidation states $(\mathrm{I}-\mathrm{V})$. The preparation of $99 \mathrm{mTc}$ pharmaceuticals is greatly facilitated by the availability of commercial cold kits containing the chemical ingredients as a lyophilized formulation ready for labeling with $99 \mathrm{mTc}$-pertechnetate [28]. The $99 \mathrm{mTc}$ generation process is as follows [27] :

Although ${ }^{99 \mathrm{~m}} \mathrm{Tc}$ is not stable, its half-life is so long $\left(2.14 \times 10^{5} \mathrm{yr}\right)$ that it can be considered stable from practical point of view and it does not have any adverse effect on human body. It can be produced in the laboratory from the parent radionuclide ${ }^{99} \mathrm{Mo}$, which has a reasonably long half-life (66hr). 


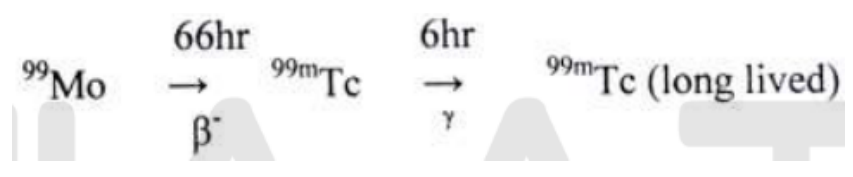

\section{Radioisotope renography}

Radioisotope renography is a form of kidney imaging involving radioisotopes. The two most common radiolabelled pharmaceutical agents used are 99mTc-MAG3 (Mercaptoacetyltriglycine) and 99mTc -DTPA (Diethylene Triamine PentacaeticAcid). Some other radiolabelled pharmaceuticals are EC (Ethyl Cysteine) and 131-Iodine labelled OIH (Ortho Iodo Hippurate). MAG3 is by far a better diagnostic agent than Tc-99m-DTPA, particularly in neonates, patients with impaired function, patients with impaired function, and patients with suspected obstruction. The MAG3 clearance is highly correlated with the effective renal plasma flow (ERPF), and the MAG3 clearance can be used as an independent measure of renal function. After intravenous administration, about 40-50\% of the MAG3 in the blood is extracted by the proximal tubules with each pass through the kidneys; the proximal tubules then secrete the MAG3 into the tubular lumen. DTPA is the second most commonly used renal radiopharmaceutical in the United States, primarily because it is the least expensive. Tc-99m-DTPA is filtered by the glomerulus and may be used to measure the glomerular filtration rate (GFR). The extraction fraction of DTPA is approximately $20 \%$, less than half that of MAG3 [27].

However, EC is preferred when the serum Creatinine is high.

\section{Preparation}

The kit contents the lyophilized ingredients in a multidose vial. Labeling is performed by adding $2-10 \mathrm{ml}$ of ${ }^{99 \mathrm{~m}} \mathrm{Tc}$ eluate containing up to $11.1 \mathrm{GBq}$ under aseptic conditions. After sterile sodium ${ }^{99 \mathrm{~m}} \mathrm{Tc}-$ pertechneate has been added to the vial, the powder is dissolved by inverting the vial. The reaction is allowed to proceed at room temperature, instructions should be followed. ${ }^{99 \mathrm{~m}} \mathrm{Tc}$ diethynetriaminepentaacetate (DTPA) complex is a sterile, pyrogen-free, clear colorless solution suitable for intravenous injection. The $\mathrm{pH}$ should be between 4.0 and 7.5 [2831].

This is an interaction in which an incident gamma photon loses enough energy to an atomic electron to cause its ejection, with the remainder of the original photon's energy emitted as a new, lower energy gamma photon whose emission direction is different from that of the incident gamma photon, hence the term "scattering". The probability of Compton scattering decreases with increasing photon energy. Compton scattering is thought to be the principal absorption mechanism for gamma rays in the intermediate energy range $100 \mathrm{keV}$ to $10 \mathrm{MeV}$. Compton scattering is relatively independent of the atomic number of the absorbing material, which is why very dense materials like lead are only modestly better shields, on a per weight basis, than are less dense materials.

\section{Imaging techniques using gamma cameras}

Scintigraphy ("scint") is the use of gamma cameras to capture emitted radiation from internal radioisotopes to create twodimensional [32] images.SPECT (single photon emission computed tomography) imaging, as used in nuclear cardiac stress testing, is performed using gamma cameras. Usually one, two or three detectors or heads, are slowly rotated around the patient's torso.

Multi-headed gamma cameras can also be used for Positron emission tomography scanning, provided that their hardware and software can be configured to detect 'coincidences' (near simultaneous events on 2 different heads). Gamma camera PET is markedly inferior to PET imaging with a purpose designed PET scanner, as the scintillator crystal has poor sensitivity for the high-energy annihilation photons, and the detector area is significantly smaller. However, given the low cost of a gamma camera and its additional flexibility compared to a dedicated PET scanner, this technique is useful where the expense and resource implications of a PET scanner cannot be justified [33].

\section{Patient preparation}

The experiment were carried out in the centre for Nuclear Medicine and Ultrasound, Rajshahi using Gamma camera. In order to evaluation the variation of glomerular filtration rate, uptake and counts per minute with renal function, 27 patients were taken under our study.

\section{Experimental procedure}

Clinical histories of the patient who came to select Nuclear Medicine Centre (CNMU, Rajshahi) for diagnosis were record. In Case of Renal function imagine normally ${ }^{99 \mathrm{~m}} \mathrm{Tc}$-DTPA were used and image is taken after a certain time when maximum number of activities accumulate to the target organ.

At first the injected dose is calibrated by the dose calibrator. About $3 \mathrm{mCi}{ }^{99 \mathrm{~m}} \mathrm{Tc}$ with DTPA are taken into

the syringe. With the help of gamma camera, the pre syringe counts (in Kcpm units) and post syringe counts (Kcpm units) are measured. From the value of pre syringe counts and post syringe counts, the net injected counts are measured. Then the patient is placed on the imaging beds and the detector of the gamma camera is placed on the suitable position. The gamma rays are counted by the detector of the gamma camera, in which emits from the kidney of the patients and the display unit shows the curve time versus counts per minute, Renal split function, uptake, Glomerular filtraration rate, kidney depth, and time of maximum counts for left and right kidney respectively by automated software (Easy softSemence signature series) programm. 


\section{Results}

A total of 27 patients were enrolled in this study. The renal split function were investigated in the range of (89.99 22.4)\% for left kidney and also (99.6 6.377)\% for right kidney. It was found that the range of uptake(\%), (8.019 2.2236)\% for left kidney and (7.765 1.19)\% for right kidney. The GFR were found in the range of (72.4 20.4) $\mathrm{ml} / \mathrm{min}$ for left kidney and also (70.9 3.937) for right kidney. Therefore, there was a mean GFR range (118 60) $\mathrm{ml} / \mathrm{min}$ for the study patients [Table 1].

\section{Discussion}

To study the variation of kidney counts, uptake and Glomerular filtration rate with renal split function, 27 patient's renogram data were taken. The renal split function were linearly influenced by kidney counts (CPM), uptake (\%) of ${ }^{99 m}$ TC-DTPA and glomerular filtration rate (GFR). The Split function versus kidney counts curves for left and right kidney are shown in Fig. 1 and Fig. 2 using Table 1. From those curve we found that the kidney counts (cpm) were increased with increasing of split function but in case of special kidney disease the kidney counts might be very low.

The split function versus uptake curve for left and right kidney are shown in Fig. 3 and Fig. 4 using Table 1. From those curve we found that the uptake (\%) were linearly increased with increasing of split function. The split function versus glomerular filtration rate (GFR) curve for left and right kidney are shown in Fig. 5 and Fig. 6 using Table 1. From those curve we found that the GFR was linearly increased with increasing of split function. But from the Fig. 7, we found that the GFR was decreased with increasing patient age.

Glomerular filtration rate is usually calculated using a mathematical formula that compares a person's size, age, sex, and race to serum creatinine levels. In most healthy people, the normal GFR is $90 \mathrm{~mL} / \mathrm{min} / 1.73 \mathrm{~m}^{2}$ or higher. A result of 60 $89 \mathrm{~mL} / \mathrm{min} / 1.73 \mathrm{~m}^{2}$ without kidney damage may be normal in some people (such as the elderly, infants). A GFR under $60 \mathrm{~mL} / \mathrm{min} / 1.73 \mathrm{~m}^{2}$ may mean kidney disease - the lower the GFR number, the worse the kidney function. This number is an estimated. It may not be a good measure of kidney health in some people, such as the very young or very old, amputees, or obese people [34].

The level of GFR and its magnitude of changeover time are vital to the detection of kidney disease, and understanding its severity and making decisions about diagnosis, prognosis, and treatment Normal GFR varies according to age, sex, and body size; in young adults it is approximately $120-130 \mathrm{~mL} / \mathbf{m i n} / \mathbf{1} .73 \mathbf{~ m}^{2}$ and declines with age. A decrease in GFR precedes the onset of kidney failure; therefore, a persistently reduced GFR is a specific diagnostic criterion for chronic kidney disease (CKD). Below $60 \mathrm{~mL} / \mathbf{m i n} / \mathbf{1} .73 \mathbf{~ m}^{2}$, the pre valence of complications of CKD increases, as does the risk of cardiovascular disease (CVD) [35].

From the Table 1 we found that the ratio between GFR and split function for left kidney is approximately equal to the ratio between GFR and split function for right kidney for every patient. Again From the Table 1, we found that the ratio between uptake and split function for left kidney is approximately equal to the ratio between uptake and split function for right kidney for every patient and the value of this ratio is approximately equal to the 0.1 . The cumulative frequency of the patients are linearly increased by the uptake (\%) of radiotracer ${ }^{99 \mathrm{~m}} \mathrm{Tc}$ (Fig.8.11). The glomerular filtration rate (GFR) was linearly increased with renal split function but decreased with patient's age. Majority patients had received (3-6)\% ${ }^{99 \mathrm{~m}}$ TC-DTPA for left kidney but (0-6)\% uptake ${ }^{99 \mathrm{~m}}$ TC-DTPA for right kidney in this research. On the other hand, majority patient had been investigated (20-30) GFR ( $\mathrm{ml} / \mathrm{min}$ ) for left kidney but (40-50) GFR ( $\mathrm{ml} / \mathrm{min}$ ) was evaluated for right kidney. Therefore, majority patient were affected in cardiovascular disease (CVD).

\section{Conclusions}

Glomerular filtration rate (GFR) was affected by kidney counts (CPM), ${ }^{99 \mathrm{~m}} \mathrm{Tc}-\mathrm{DTPA}$ uptake (\%) and the renal split function. The GFR was linear relationship with renal split functions but linearly decreased with patient's age. For majority patients, the calculated value of GFR were (20-30) $(\mathrm{ml} / \mathrm{min})$ and $(40-50)(\mathrm{ml} / \mathrm{min})$ in left and right kidney respectively. Therefore, majority patient were affected in cardiovascular disease (CVD). In future from this research, a doctor or a medical physicists will be able to identify that the renal function of a patient is damage or good.

Conflict of interest The author declares that he has no conflict of interest.

\section{ACKNOWLEDGMENTS}

The author would like to thank Institute of Nuclear Medicine and Allied Sciences, Rajshahi, Bangladesh , for providing data supply.

\section{References}

[1].Prigent A, Cosgriff P, Gates GF, Granerus G, Fine EJ, Itoh K, et al. Consensus report on quality control of quantitative measurements of renal function obtained from the renogram: International consensus committee from the Scientific Committee of Radionuclides in Nephrourology. Semin Nucl Med . 1999; 29: 146-159

[2].Gates GFGlomerular filtration rate: Estimation from fractional renal accumulation of 99mTc-DTPA (stannous). AJR. 1982;138: 565-570

[3].Russell CD, Bischoff PG, Kontzen F, Rowell KL, Yester MV, Lloyd LK, et al. Measurement of glomerular filtration rate using 99mTc-DTPA and the gamma camera: a comparison of methods. EurJ Nucl Med. 1985;10: 519-521.

[4].Fawdry RM, Grueneward SM, Collins LT, Roberts AJ. Comparative assessment of techniques for estimation of glomerular filtration rate with Tc-99m-DTPA. Eur J Nucl Med. 1985; 11: 7-12. 
[5].Russell CD, Dubovsky EV. Gates method for GFR measurement [letters to the editor]. J Nucl Med. 1986;27: 13731374.

[6].Russell CD. Estimation of glomerular filtration rate using 99mTc-DTPA and the gamma camera. Eur J Nucl Med. 1987;12: 548-552.

[7].Mulligan JS, Blue PW, Hasbargen JA. Methods for measuring GFR with technetium-99m-DTPA: an analysis of several common methods. J Nucl Med. 1990; 31: 1211-1219.

[8].Goates JJ, Morton KA, Whooten WW, Greenberg HE, Datz FL, Handy JE, et al. Comparison of methods for calculating glomerular filtration rate: technetium-99m-DTPA scintigraphic analysis, protein-free and wholeplasma clearance of technetium-99m-DTPA and iodine-125-iothalamate clearance. J Nucl Med. 1990; 31: 424- 429.

[9].Duran E, Prigent A, Gaillard J. Comparison between 9 methods for estimation of glomerular filtration rate (GFR) with simultaneous injection of 51Cr-EDTA and 99mTc-DTPA. In: Taylor A Jr, Nally J, Thomsen H (eds), Radionuclides in Nephrourology, Reston, VA; Society of Nuclear Medicine. 1997; 112-120.

[10]. De Santo NG, Anastasio P, Cirillo M, Santoro D, Spitali L, Mansi L, et al. Measurement of glomerular filtration rate by the $99 \mathrm{mTc}-\mathrm{DTPA}$ renogram is less precise than measured and predicted creatinine clearance. Nephron. 1999; 81: $136-140$.

[11]. Itoh K, Tsushima S, Tsukamoto E, Tamaki N. Reappraisal of single-sample and gamma camera methods for determination of the glomerular filtration rate with 99mTc-DTPA. Ann Nucl Med. 2000; 14: 143-150.

[12]. Cockcroft DW, Gault MH. Prediction of creatinine clearance from serum creatinine. Nephron. 1976;16: 31-41.

[13]. Brochner-Mortensen J. Routine methods and their reliability for assessment of glomerular filtration rate in adults with special reference to total [51Cr]EDTA plasma clearance. Dan Med Bull. 1978;25: 181-202.

[14]. Brochner-Mortensen J. Current status on assessment and measurement of glomerular filtration rate. Clin Physiol. 1983;8: 1-17.

[15]. Levey AS. Use of measurements of GFR to assess the progression of renal disease. Semin Nephrol. 1989;9: 370378.

[16]. Blaufox MD, Aurell M, Bubeck B, Fommei E, Piepsz A, Russell C, et al. Report of the Radionuclides in Nephrourology Committee on renal clearance. J Nucl Med. 1996;37: 1883-1890.

[17]. Goates, JJ,. Morton KA, Whooten WW, Greenberg HE, Datz FL, Handy JE. Comparison of methods for calculating glomerular filtration rate: technetium-99m-DTPA scinti-graphic analysis, protein-free and wholeplasma clearance of technetium-99m-DTPA and iodine-125-iothalamate clearance. NucL Med. 1990;31: 424429.

[18]. Taylor A, Nally JV. Clinical applications of renal scintigraphy. Am. J. Roentgenol. AJR. 1995;164(1): 31-41.

[19]. Hackstein N, Buch T, Rau WS, Weimer R, Klett R. Split renal function measured by triphasic helical CT. Eur. J. Radiol. 2007;61: 303-309.

[20]. Yura T, Takamitsu Y, Yuasa S, Miki S, Takahashi N, Bandai H, Sumikura T, Uchida K, Tamai T, Matsuo H. Total and split renal function assessed by ultrasound Doppler techniques. Nephron. 1991;58: 37-41.

[21]. Daniel GB, Mitchell SK, Mawby D, Sackman JE, Schmidt D. Renal nuclear medicine: a review. Vet. Radiol. Ultrasound. 1999;40: 572-587.

[22]. Miyazaki C, Harada H, Shuke N, Okizaki A, Miura M, Hirano T. (99m)Tc-DTPA dynamic SPECT and CT volumetry for measuring split renal function in live kidney donors. Ann. Nucl. Med. 1999;24: 189-195.

[23]. Ritchie G, Wilkinson AG, Prescott RJ. Comparison of differential renal function using technetium-99m mercaptoacetyltriglycine (MAG3) and technetium-99m dimercaptosuccinic acid (DMSA) renography in a paediatric population. Pediatr. Radiol. 2008;38: 857-862.

[24]. Summerlin AL, Lockhart ME, Strang AM, Kolettis PN, Fineberg NS, Smith JK. Determination of split renal function by 3D reconstruction of CT angiograms: a comparison with gamma camera renography. AJR Am. J. Roentgenol. 2008; 191: 1552-1558.

[25]. Itoh K. 99mTc-MAG3: review of pharmacokinetics, clinical application to renal diseases and quantification of renal function. Ann. Nucl. Med. 2001;15: 179-90.

[26]. Moran JK. Technetium-99m-EC and other potential new agents in renal nuclear medicine. Semin. Nucl. Med. 1999;29: 91-101.

[27]. Sodee DB, Early PJ. Technologyand interpretation of nuclear medicine procedures, second Edition, st. Louis, C.V. Mosby company.1975;520.

[28]. Atkins HL, Eckelman WC, Hauser W, Klopper JF, Richards $P$. Evaluation of glumerular fitration rate with ${ }^{99 \mathrm{~m}} \mathrm{Tc}-$ DTPA . J Nucl Med. 1971;12:338.

[29]. Chowdhuri TK. Use of ${ }^{99 m}$ Tc-DTPA for measuring gastric emptying time . J Nucl Med. 1974;15:391-395.

[30]. Coats G, O'Brodovich H. Measurement of pulmonary epithetlial permeability with ${ }^{99 m}$ Tc -DTPA aerosol .Semin Nucl Med. 1986;16(4):275-284

[31]. Hauser W, Atkins HL, Nelson KG, Richards P. Technetium- ${ }^{99 m}$ Tc -DTPA: a new radiopharmaceuticals for brain and kidney scanning . Radiology . 1970; 94(3):679-684.

[32]. Cardiol J, Cerqueira MD et al. Recommendations for reducing radiation exposure in myocardial perfusion imaging. J Nucl Cardio. 2010; 17: 709-718.

[33]. Dorland's Medical Dictionary for Health Consumers, by Saunders; Saunders Comprehensive Veterinary Dictionary, 3 ed. 2007; McGraw-Hill Concise Dictionary of Modern Medicine, 2002 by The McGraw-Hill Companies.

[34]. ADAMMultimediaEncyclopedia,Availablefrom http://pennstatehershey.adam.com/content.aspx?productId=117\&pid=1\&gid=007305 
[35]. CardioSma $\quad$ rt,
https://www.cardiosmart.org/healthwise/aa15/4102/aa154102

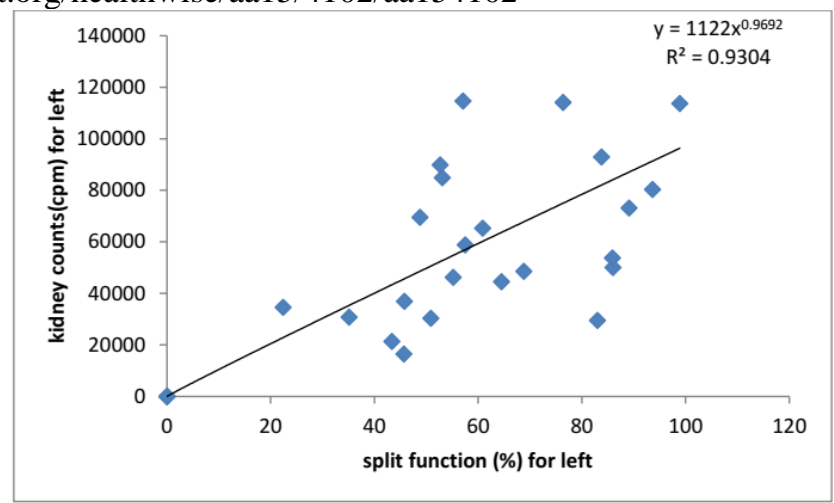

Fig. 1 Split function versus Kidney counts curve(for left kidney scan)

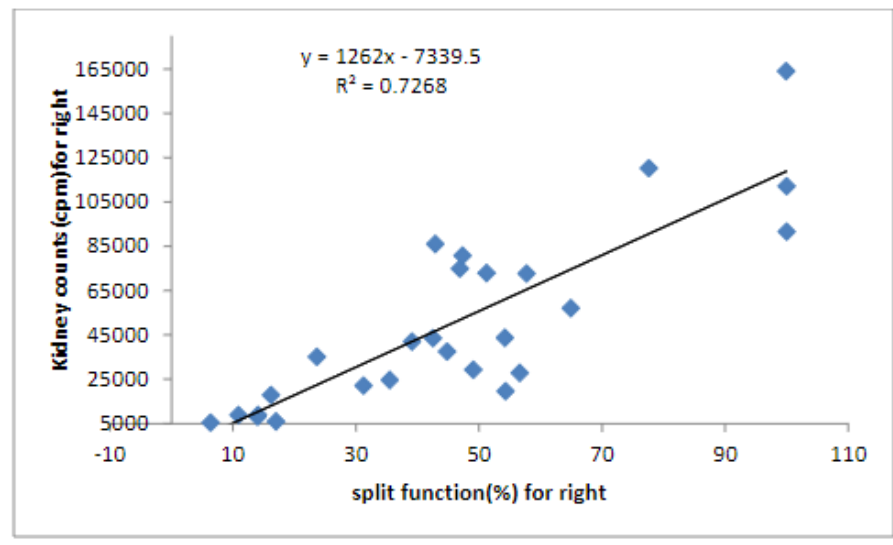

Fig. 2 Split function versus Kidney counts curve(for right kidney scan)

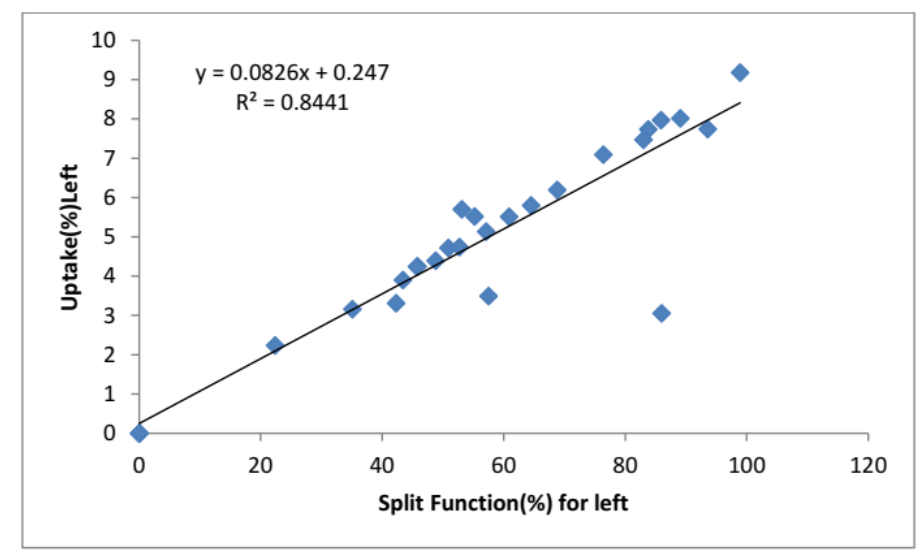

Fig. 3 Split function versus uptake curve(for left kidney scan) 


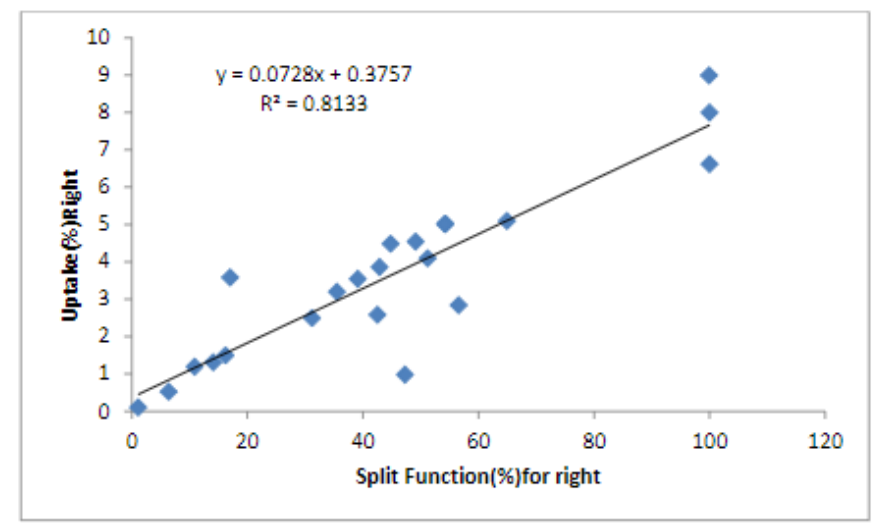

Fig. 4 Split function versus uptake curve(for right kidney scan)

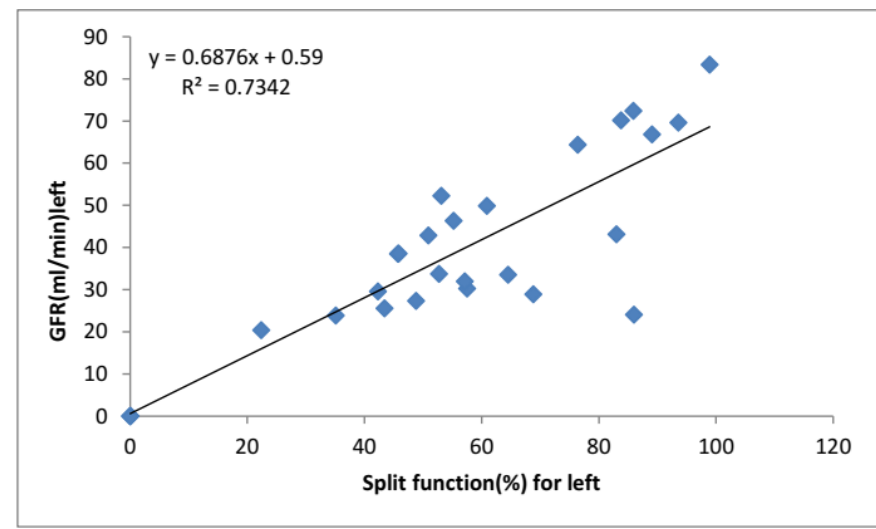

Fig. 5 Split function versus GFR curve(for left kidney scan)

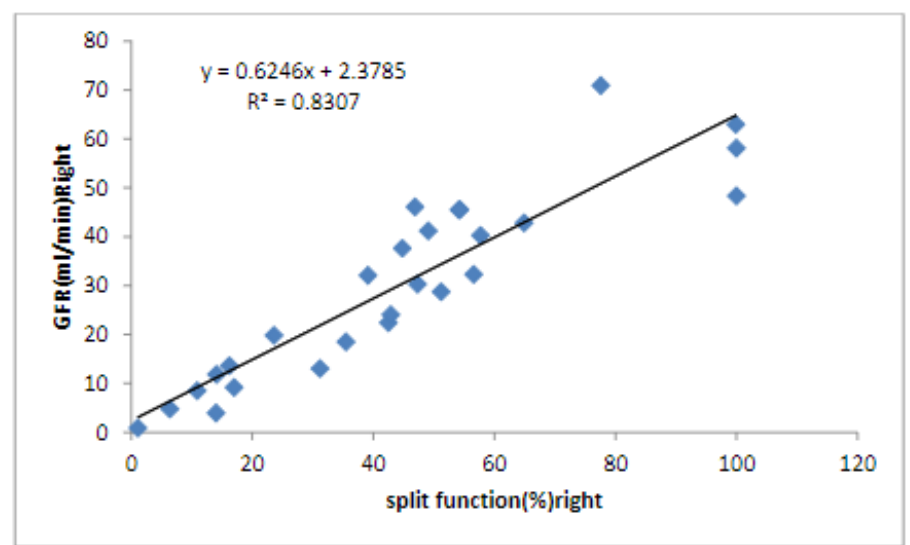

Fig. 6 Split function versus GFR curve(for right kidney scan) 


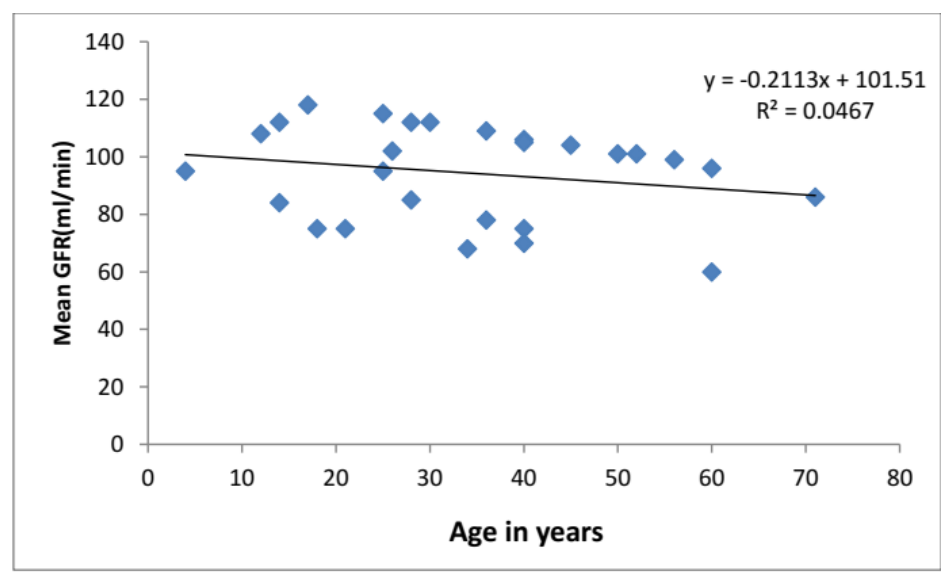

Fig. 7 Age versus mean GFR curve(for kidney scan)

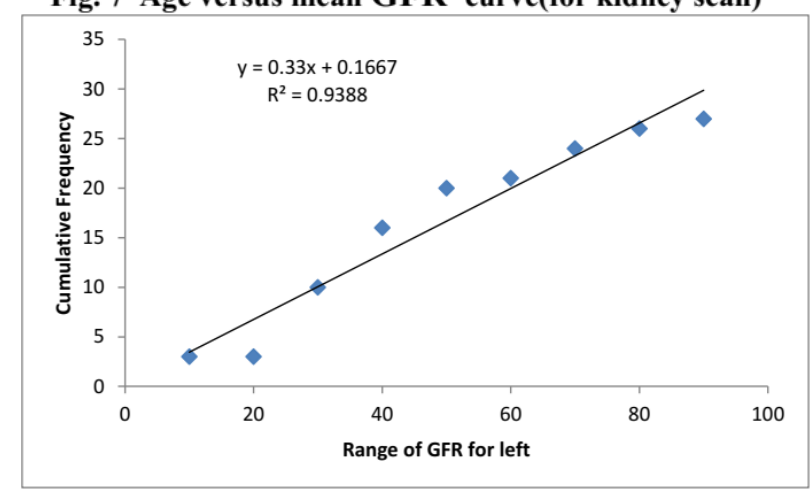

Fig. 8 Range of GFR versus cumulative frequency curve(for left kidney scan)

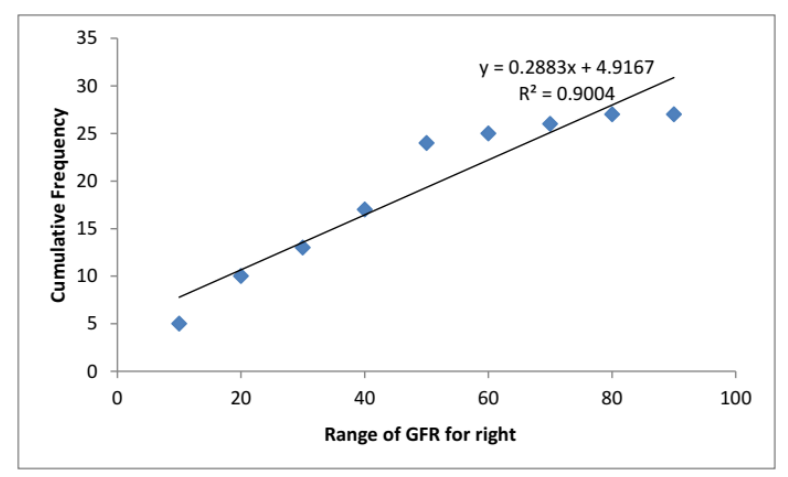

Fig. 9 Range of GFR versus cumulative frequency curve(for right kidney scan)

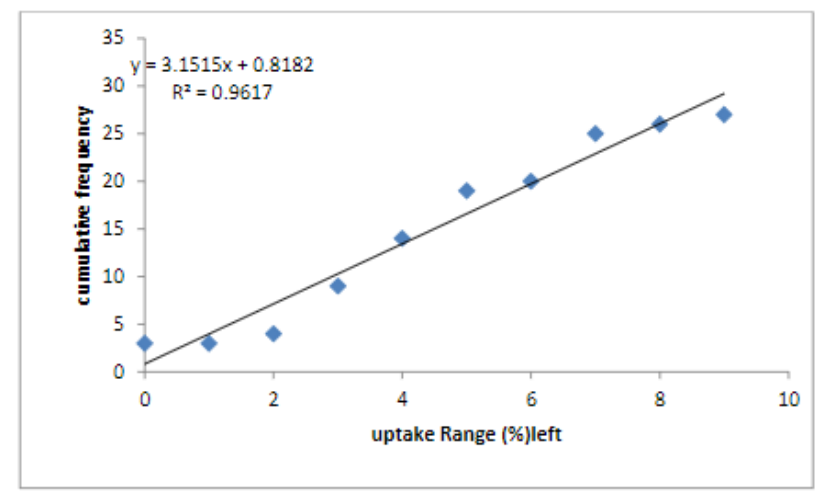

Fig. 10 Uptake range versus cumulative frequency curve(for left kidney scan) 


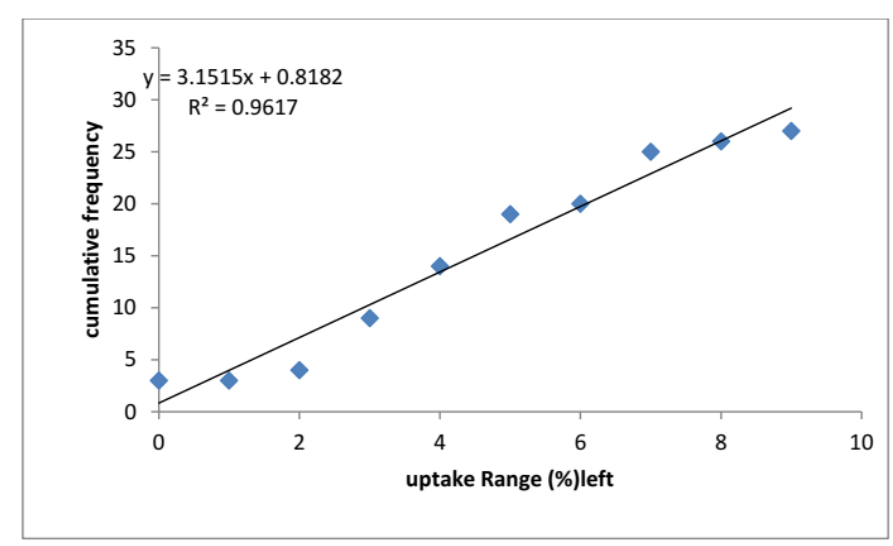

Fig. 10 Uptake range versus cumulative frequency curve(for left kidney scan)

Table 1 Split function and Glumerolur filtration rate (GFR) measured by Gamma camera due to administration of ${ }^{99 \mathrm{~m}} \mathrm{Tc}$-DTPA for left and right kidney

\begin{tabular}{|c|c|c|c|c|c|c|c|c|c|c|c|c|}
\hline Age & $\begin{array}{l}\text { Split } \\
\text { fenction(6)inteft }\end{array}$ & $\begin{array}{l}\text { Split } \\
\text { fenction(\%)right }\end{array}$ & $\begin{array}{l}\text { Kidney } \\
\text { Countsicpas)Left }\end{array}$ & $\begin{array}{l}\text { Kidney } \\
\text { Coums } \\
\text { (cpan)Righat }\end{array}$ & $\begin{array}{l}\text { Tptahe(\%) } \\
\text { Left }\end{array}$ & $\begin{array}{l}\text { Uptake(\%) } \\
\text { Right }\end{array}$ & CFRY(mV/min $) \mathrm{keft}$ & 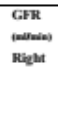 & $\begin{array}{l}\text { Ratio between GFR } \\
\text { And split fuace. } \\
\text { (for keft Lianey) }\end{array}$ & 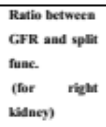 & $\begin{array}{l}\text { Ratio betneet } \\
\text { aptake and } \\
\text { split fuascion } \\
\text { (for keft } \\
\text { kidtasy) }\end{array}$ & $\begin{array}{l}\text { Ratio betweet } \\
\text { uptake and } \\
\text { split function } \\
\text { (bor right } \\
\text { Lidaney) }\end{array}$ \\
\hline 7 & 22.4 & 77.6 & 34625 & 120246 & 2.236 & 7.765 & 20.4 & 70.9 & 0.911 & 0.913 & 0.099 & 0.100 \\
\hline 40 & 42.3 & 57.7 & 533655 & 72706 & 3.311 & 4.511 & 29.6 & 40.3 & 0.699 & 0.698 & 0.078 & 0.078 \\
\hline 30 & 76.4 & 23.6 & 114139 & 35164 & 7.092 & 2.185 & 64.4 & 19.8 & 0.842 & 0.838 & 0.092 & 0.093 \\
\hline 17 & 53.1 & 46.9 & 84970 & 74904 & 5.700 & 5.025 & 52.3 & 46.1 & 0.985 & 0.983 & 0.107 & 0.107 \\
\hline 50 & 86 & 14 & 50122 & 8176.9 & 3.057 & 0.499 & 24.1 & 3.937 & 0.280 & 0.281 & 0.035 & 0.035 \\
\hline 25 & 0.039 & 100 & 36 & 91590 & 0.003 & 6.612 & 0.023 & 58.1 & 0.590 & 0.581 & 0.077 & 0.066 \\
\hline 45 & 93.6 & 6.377 & 80413 & 5477.4 & 7.747 & 0.528 & 69.6 & 4.743 & 0.744 & 0.744 & 0.082 & 0.082 \\
\hline 52 & 60.9 & 39.1 & 65306 & 42009 & 5.512 & 3.546 & 49.9 & 32.1 & 0.820 & 0.820 & 0.090 & 0.091 \\
\hline 36 & 83.8 & 16.2 & 92941 & $\begin{array}{l}17958 \\
\end{array}$ & 7.736 & 1.495 & 70.2 & 13.6 & 0.838 & 0.839 & 0.092 & 0.092 \\
\hline 56 & 57.5 & 42.5 & 58899 & 43556 & 3.491 & 2.582 & 30.3 & 22.4 & 0.527 & 0.527 & 0.061 & 0.061 \\
\hline 14 & 50.9 & 49.1 & 30425 & 29346 & 4.72 & 4.54 & 42.9 & 41.19 & 0.843 & 0.840 & 0.092 & 0.092 \\
\hline 12 & 45.7 & 54.3 & 16537 & 19637 & 4.24 & 5.02 & 38.52 & 45.55 & 0.843 & 0.841 & 0.092 & 0.092 \\
\hline 26 & 45.8 & 54.2 & 36989 & 43777 & 4.252 & 5.01 & 38.6 & 45.47 & 0.843 & 0.841 & 0.093 & 0.092 \\
\hline 40 & 98.9 & 1.069 & 113680 & 1228.4 & 9.18 & 0.099 & 83.36 & 0.897 & 0.842 & 0.839 & 0.092 & 0.092 \\
\hline 60 & 85.9 & 14.1 & 53830 & 8860.1 & 7.97 & 1.31 & 72.4 & 11.82 & 0.843 & 0.838 & 0.093 & 0.093 \\
\hline 4 & 55.2 & 44.8 & 46253 & 37501 & 5.52 & 4.48 & 46.37 & 37.63 & 0.840 & 0.840 & 0.1 & 0.1 \\
\hline 71 & 64.5 & 35.5 & 44621 & 24608 & 5.805 & 3.195 & 33.54 & 18.46 & 0.520 & 0.521 & 0.090 & 0.090 \\
\hline 14 & 0.063 & 99.9 & 98.8 & 16110 & 0.00567 & 8.991 & 0.04 & 62.93 & 0.635 & 0.630 & 0.090 & 0.090 \\
\hline 21 & 57.1 & 42.9 & 114729 & 86116 & 5.139 & 3.861 & 31.98 & 24.03 & 0.560 & 0.560 & 0.090 & 0.090 \\
\hline 60 & 68.8 & 31.2 & 48638 & 22083 & 6.192 & 2.496 & 28.9 & 13.04 & 0.420 & 0.417 & 0.090 & 0.080 \\
\hline 40 & 48.8 & 51.2 & 69610 & 72963 & 4.392 & 4.096 & 27.33 & 28.7 & 0.560 & 0.561 & 0.090 & 0.080 \\
\hline 40 & 83 & 17 & 29548 & 6038 & 7.47 & 3.584 & 43.16 & 9.18 & 0.520 & 0.540 & 0.090 & 0.085 \\
\hline 28 & 89.1 & 10.9 & 73202 & 8948 & 8.019 & 1.19 & 66.825 & 8.502 & 0.750 & 0.740 & 0.090 & 0.109 \\
\hline 25 & 52.7 & 47.3 & 89863 & 80810 & 4.743 & 0.981 & 33.728 & 30.27 & 0.640 & 0.639 & 0.090 & 0.090 \\
\hline 18 & 43.4 & 56.6 & 21386 & 27892 & 3.906 & 2.838 & 25.61 & 32.26 & 0.590 & 0.570 & 0.090 & 0.089 \\
\hline 34 & 0.006 & 100 & 7 & 112197 & 0.00054 & 8 & 0.0042 & 72.3 & 0.700 & 0.723 & 0.090 & 0.080 \\
\hline 36 & 35.1 & 64.9 & 30826 & 57039 & 3.159 & 5.093 & 23.87 & 42.83 & 0.680 & 0.670 & 0.090 & 0.080 \\
\hline
\end{tabular}

